\title{
Botox - Was Ihre Patienten Sie fragen werden
}

\author{
Markus Deutsch \\ für den Vorstand der Ärztinnen \\ und Ärzte für Tierschutz \\ in der Medizin
}

Den meisten Ärzten, die Botox oder die analogen Produkte Dysport und Vistabel verwenden, ist kaum bewusst, dass zur Herstellung von jeder einzelnen Charge Botox massiv belastende Tierversuche durchgeführt werden müssen. Durch die Sendung «Kassensturz» vom 20. November 2007 ist die Problematik der hiermit verbundenen leidvollen Tierversuche der Öffentlichkeit bekannt geworden. Wir möchten die Ärzteschaft deshalb mit diesen Zeilen über diese Problematik von Botox informieren.

\section{Was ist das Problem mit Botox?}

Da Botox ein starkes Nervengift ist, das rasch einmal tödlich überdosiert werden könnte, muss der Gehalt an Botox in jeder Produktionseinheit (Charge) überprüft werden. Hierzu spritzt man Mäusen Botox in die Bauchhöhle und bestimmt die Dosis, die es braucht, bis 50\% der Tiere tot sind (sogenannter LD50-Test).

Diese Tiere sterben aber nicht einfach so, sondern erleiden einen qualvollen Tod durch die Nervenlähmungen, bis sie schliesslich an der Lähmung der Atmung ersticken. Dies kann mehrere Tage dauern.

\section{Sind diese Versuche nicht alle schon längst vorbei, so dass die jetzige Verwendung \\ keine neuen Tiere quält?}

Leider nein. Pro Produktionseinheit müssen die Tests immer wieder neu durchgeführt werden. Das heisst: Je mehr Botox verbraucht wird, desto mehr Tierversuche werden gemacht.

\section{Wie werden die Tierversuche zur Produktion von Botox von Fachleuten eingeschätzt?} Hier die Aussage des Baselbieter Kantonstierarztes Ignaz Bloch, Mitglied der Eidgenössischen Tierversuchskommission, im «Kassensturz» vom 20. November 2007: «Ein solcher Tierversuch würde bei uns nie bewilligt werden, weder von mir noch von der kantonalen Tierversuchskommission.» Botox dürfte also nach Schweizer Gesetzen weder bewilligt noch produziert werden.

\section{Wie viele Mäuse müssen für Botox \\ jährlich qualvoll sterben?}

Diese Zahlen werden von den Produzenten streng geheimgehalten. Ein Insider, Prof. Hans Bigalke, Toxikologe in Hannover, der eine Alternativmethode entwickelt, schätzt die jährliche Anzahl Mäuse auf 100000, es können gemäss Prof. Bigalke aber auch 200000 oder 300000 Tiere sein.

Nachdem die Hersteller seit Jahren jegliche Stellungnahme zu den Versuchstierzahlen ab- lehnen, kann man getrost davon ausgehen, dass die effektiven Zahlen höher und nicht tiefer liegen.

\section{Um wieviel Geld geht es bei Botox?}

Gemäss dem Jahresbericht 2006 von Allergan (Hersteller von Botox) wurde Botox zum Blockbuster. 982 Millionen US-Dollar wurden 2006 umgesetzt, hinzu kommt der Umsatz in Japan und China. Der Umsatz von Botox stieg von 2005 auf 2006 um 24\% und derjenige im kosmetischen Bereich gar um 32\%.

Gibt es keine Alternativen zu diesen Tierversuchen? Das Problem ist von der Industrie erkannt. Es gibt eine Reihe von Alternativen zu diesem LD50-Test (SNAP-25 Endopeptidase Activity Assay, Intercostalmuskelpräparat, Nervus-phrenicus-Zwerchfellpräparat, ELISA-Tests). Die Tierversuchszahlen konnten laut Angaben der Industrie vermindert werden. Der Ersatz der LD50Tests scheitert bisher aber offenbar vor allem an der fehlenden Kooperation der herstellenden Firmen untereinander, die sich auf einen gemeinsamen Alternativtest einigen müssten.

Ist Botox ein Medikament oder ein Kosmetikartikel? Die Geschäftsberichte der letzten vier Jahre von Allergan zeigen: Der Umsatz von Botox machte im kosmetischen Bereich 2003 40\% aus, 42\% im Jahr 2004, 43\% 2005 und 2006 bereits 48\%. Die Hälfte von Botox wird also aus kosmetischer Indikation eingesetzt.

Sind Produktion und Vertrieb eines Produkts, das vorwiegend ein Kosmetikartikel ist, mit dem Tierschutzgesetz vereinbar?

Tierversuche für Kosmetika werden in der Schweiz seit einigen Jahren nicht mehr durchgeführt und werden europaweit abgeschafft. Wie oben erwähnt dürften die für Botox notwendigen Tierversuche in der Schweiz nicht durchgeführt werden. Um so weniger ist zu verstehen, warum Botox dann für kosmetische Verwendung im Ausland getestet und in die Schweiz importiert werden darf.

Was können wir gegen diese Tierversuche tun? Wir können das Produkt zumindest bei kosmetischen Indikationen meiden, bis akzeptable Alternativmethoden anerkannt sind. Dies würde auch den Druck auf die Herstellerfirmen erhöhen, besser zusammenzuarbeiten und die Alternativmethoden zu etablieren. 